\title{
Methods for monitoring land subsidence and earth fissures in the Western USA
}

\author{
K. C. Fergason, M. L. Rucker, and B. B. Panda \\ Amec Foster Wheeler, Phoenix, Arizona, USA \\ Correspondence to: K. C. Fergason (ken.fergason@amecfw.com) \\ Published: 12 November 2015
}

\begin{abstract}
Depletion of groundwater resources in many deep alluvial basin aquifers in the Western USA is causing land subsidence, as it does in many regions worldwide. Land subsidence can severely and adversely impact infrastructure by changing the ground elevation, ground slope (grade) and through the development of ground cracks known as earth fissures that can erode into large gullies. Earth fissures have the potential to compromise the foundations of dams, levees, and other infrastructure and cause failure.

Subsequent to an evaluation of the overall subsidence experienced in the vicinity of subsidence-impacted infrastructure, a detailed investigation to search for earth fissures, and design and/or mitigation of potentially effected infrastructure, a focused monitoring system should be designed and implemented. Its purpose is to provide data, and ultimately knowledge, to reduce the potential adverse impacts of land subsidence and earth fissure development to the pertinent infrastructure. This risk reduction is realized by quantifying the rate and distribution of ground deformation, and to detect ground rupture if it occurs, in the vicinity of the infrastructure.

The authors have successfully designed and implemented monitoring systems capable of quantifying rates and distributions of ground subsidence and detection of ground rupture at multiple locations throughout the Western USA for several types of infrastructure including dams, levees, channels, basins, roadways, and mining facilities. Effective subsidence and earth fissure monitoring requires understanding and quantification of historic subsidence, estimation of potential future subsidence, delineation of the risk for earth fissures that could impact infrastructure, and motivation and resources to continue monitoring through time. A successful monitoring system provides the means to measure ground deformation, grade changes, displacement, and anticipate and assess the potential for earth fissuring. Employing multiple methods, a monitoring strategy utilizes an integrated approach, including both regional and local measurements.

Various methods implemented include conventional practices and proven, instrumented in-ground sensing systems. The conventional techniques include repeat optical levelling and global positioning system (GPS) surveys, ground reconnaissance, photo-geological analysis, groundwater monitoring, and tape-extensometers. Advanced techniques include the processing and interpretation of differential interferograms of repeat-pass, satellite-based synthetic aperture radar data (InSAR), borehole tiltmeters, microseismic arrays, excavation of monitoring trenches, and time-domain reflectometry (TDR).
\end{abstract}

\section{Introduction}

Depletion of groundwater resources in many deep alluvial basin aquifers in the Western USA is causing land subsidence, as it does in many regions worldwide. Land subsidence can severely and adversely impact infrastructure by changing the ground elevation, ground slope (grade) and through the development of ground cracks known as earth fissures that can erode into large gullies. Earth fissures have the potential to compromise the foundations of dams, levees, and other infrastructure and cause failure.

The authors have a combined experience of over 50 years for characterizing, predicting, monitoring and remediation at project sites where ground subsidence and/or earth fissuring are impacting infrastructure (Rucker and Keaton, 
1996, 1998; Keaton et al., 1998; Weeks et al., 2004; Weeks and Panda, 2004; Rucker and Fergason, 2004; Rucker and Holmquist, 2006; Rucker et al., 2008, 2013; Panda et al., 2013; Fergason et al., 2013, 2014). This includes a power generating plant in southeast Arizona where annual subsidence and earth fissure monitoring has been performed by the authors for over 20 years. The authors perform regular land subsidence and/or earth fissure related monitoring at over ten additional sites that include dams, levees, flood retarding structures, flood control basins and channels, a liquefied petroleum gas storage facility, large gold and copper mines, and at a brine cavern at risk for catastrophic collapse. The authors are currently involved in developing land subsidence and/or earth fissure monitoring for several additional projects, including the California High-Speed Rail network.

\section{Monitoring methods}

Various methods implemented include conventional practices and proven, instrumented in-ground sensing systems. The conventional techniques include repeat optical levelling and global positioning system GPS surveys, ground reconnaissance, photo-geological analysis, groundwater monitoring, and tape-extensometers. Advanced techniques include the processing and interpretation of InSAR, borehole tiltmeters, microseismic arrays, excavation of monitoring trenches, and TDR. The sections below summarize land subsidence and earth fissure monitoring methods that have been deployed in the Western USA.

\subsection{Survey}

The use of survey techniques provides a means of forming a network for various instrumentation systems, with the approach being an effective method to monitor ground deformation. Due to the often gradual and small relative movements to be measured for ground subsidence, verification of accuracy is a critical aspect of this portion of the measurement program. Multiple survey techniques can be utilized: (1) conventional optical levelling techniques, (2) real-time kinematics (RTK), and (3) static GPS observations. When constructing survey monuments for the purpose of land subsidence monitoring, proper foundations must be achieved that prevent near-surface ground deformation associated with hydrocompaction of near-surface soils, near-surface settlement of soils and/or fill material, freeze-thaw cycles, and other seasonal near-surface ground deformation.

\subsubsection{Optical levelling}

Conventional optical levelling remains one of the most reliable and most economic methods for obtaining highly accurate elevation data at the scale that most land subsidence occurs. Relational elevation differences between dedicated survey monuments should be determined through the use of dif- ferential digital level loops, or conventional level techniques. When plausible, these measurements should be taken in relation to a stable bedrock benchmark, however it is often sufficient to observe relative differences without a direct tie to a stable point. Elevations measured by levelling should be expected to meet an accuracy of at least $\pm 3 \mathrm{~mm}$ and monument spacing needs to be planned to achieve that level of accuracy.

\subsubsection{RTK GPS}

RTK GPS methods are typically the quickest and most economical survey techniques available. However, RTK GPS survey techniques do not have the level of vertical accuracy as other survey techniques. Elevations measured by RTK should be expected to meet an accuracy of at least $\pm 21 \mathrm{~mm}$ at $95 \%$ confidence ratio and monument spacing needs to be planned to achieve that level of accuracy.

\subsubsection{Static GPS}

Static GPS methods have the capability of obtaining horizontal and vertical positions with relatively high accuracy and can be utilized to measure both horizontal and vertical deformation due to land subsidence and earth fissuring. Maximum care in setup on monuments and measuring height of the instruments, should be observed. When practical, a permanent or dedicated mount for a GPS antenna may be used to reduce potential setup error. A minimum accuracy of $\pm 5 \mathrm{~mm}$ horizontal and $\pm 20 \mathrm{~mm}$ vertical should be achieved and monument spacing needs to be planned to achieve that level of accuracy. Achieving such accuracy using static GPS may require that each point, including bedrock or offsite reference, be occupied for $1.5 \mathrm{~h}$ or more with a minimum of 5 visible satellites.

\subsection{Photo-geologic analysis}

Traditional low-sun-angle (LSA) aerial photography lineament analysis for the purpose of searching for earth fissures was first described in detail by Beckwith et al. (1991) and can be utilized as a regular monitoring tool to assess changes in a subsiding landscape. These features include elongated earth fissure gullies, alignments of potholes and other small depressions, lineations in the vegetative cover, deflation features, and subtle linear ground features caused by shading. A lineament analysis alone is not sufficient, and the lineament analysis must be followed by a geological reconnaissance of photo-lineaments and a terrestrial search for earth fissures.

As technology has improved, traditional LSA aerial photography has been largely replaced by high-resolution digital aerial imagery. The authors have previously assessed the use of both imagery types and determined that digital HRD imagery provides a comparable level of analysis to that provided by LSA photography (AMEC, 2013). The use of digital imagery has added benefits in that it photo-geologic lin- 
eament analyses can be performed at a lower cost and in a shorter timeframe.

The primary limitations of photo-geological lineament analysis for earth fissure searches and for use as a monitoring tool derive from the coverage and quality of the remote sensing data used for the analysis and the condition of the terrain analysed. Poor-quality remote sensing data and/or data that do not completely cover the area of interest limit the ability to conduct the analysis. Additionally, even if high-quality remote sensing data are available for the area of interest, limited temporal coverage can also limit the effectiveness of the analysis.

The condition of the analysed terrain can also significantly impact the effectiveness of the analysis. Agriculture, urbanization and other large-scale human development can obscure the ground and severely limit the effectiveness of the analysis. Other human disturbances such as off-road vehicles and historical roads can have significant impact on the terrain. Animal activity from wildlife and domestic stock such as cattle can also create significant ground disturbance. Additionally, annual and perennial vegetation can obscure lineaments. Soft, cohesionless shallow soil profiles have the ability to prevent the expression of earth fissures at the surface. Additionally, in areas where sediment is deposited by wind and/or water (such as upstream of an embankment), signs of earth fissuring may be obscured. If an earth fissure does not have a surface expression, it is unlikely that a photogeological lineament analysis would identify it.

\subsection{Geologic mapping/reconnaissance}

Regular visual ground inspection is important part of a monitoring program. The inspections should be performed by an experienced person walking the project area looking for cracks, potholes or other features which may indicate earth fissuring. Visual inspections should be performed as close in time as practicable to the other field measurements included in the monitoring program. Inspections should also be performed after major storm runoff events. Locations and descriptions of cracks, potholes and other erosional features should be documented with sketches, maps and photographs as appropriate, including locations, dimensions and orientations. The appropriate level of background work should be completed before commencing field work. This includes review of InSAR and the completion of the photo-geological analysis. Additionally, an extensive data review of all relevant reports and publications, groundwater data, survey data and remote sensing data should be performed prior to the field work.

Special care should be taken in areas where giant desiccation cracking occurs. Differentiating between giant desiccation cracks and earth fissures requires experience and additional investigation such as seismic refraction profiling and trench excavation with detailed logging.
The primary limitations to the method involve impacting the ability to observe. Annual and perennial vegetation cover can limit the ability to see signs of ground cracking. Disturbance by human activity and/or livestock and wildlife can also limit the amount of observation possible. When the ground is high in moisture content, subtle signs of ground strain such as small ground cracks may not be visible.

Other limitations and uncertainties of the method are rooted in the competency of the investigation itself. The investigators must correctly interpret the background information, InSAR and other imagery, and photo-geological results to identify the areas in need of investigation. It is critical that personnel performing the investigation have previous experience in geological reconnaissance of photo-lineaments and terrestrial search for earth fissures due to the often subtle nature of important features.

\subsection{Groundwater monitoring}

The collection of regional groundwater levels from available sources is an important component of monitoring for land subsidence and earth fissures. Understanding the groundwater trends allows for greater understanding of local and regional ground deformation trends and can aid in predicting where future deformation may occur.

\subsection{Tape extensometers}

Tape extensometers can be utilized to measure horizontal displacement between two or more points with a measurement precision of $\pm 0.01 \mathrm{~mm}$. Tape extensometer arrays utilized as part of a monitoring system can quantify the rate of deformation at a known earth fissure or can be utilized to monitor for the potential development of a new earth fissure in an area that is considered to have a high likelihood for future fissure formation. Quadrilateral arrays can be utilized to understand deformation in greater detail and determine if shear deformation is occurring.

The tape extensometer should be operated in accordance with the manufacturer's instructions, including proper tensioning and recording of ambient temperature. Grass, weeds and other possible obstructions to the tape should be cut or removed before performing readings. The author's experience with tape extensometers has shown that measurements taken during a windy day are not as accurate as those taken on calm days.

Greater horizontal movements are anticipated in a transverse direction across fissures or the trend of nearby photolineaments, and negligible movements are anticipated normal to the linear array. Thus, inherent checks of tape extensometer calibration and operation should be performed on the readings parallel to fissures as part of each measurement cycle. 


\subsubsection{Rod extensometers}

In addition to tape extensometer, experimental rod extensometers have been utilized by the authors with mixed success to monitor earth fissure at one location in Central Arizona (AMEC, 2010). Two rod extensometer arrays, each straddling a previously identified earth fissure, were installed. Each rod extensometer array consists of a $72 \mathrm{~cm}$ diameter instrument vault that houses a reference table embedded in concrete which is founded approximately $3 \mathrm{~m}$ below existing grade within stable Pleistocene-age soils. Three $46 \mathrm{~cm}$ diameter companion end-anchor encasements are also founded on Pleistocene-age soils. The spacing between each instrument vault and its three companion end anchors is approximately 12,18 and $30 \mathrm{~m}$, with the fissure positioned between the 12 and $18 \mathrm{~m}$ anchors. The intent of positioning the fissure between the 12 and $18 \mathrm{~m}$ anchors was to provide an opportunity to segment the monitoring to assess local displacement within close proximity of the fissure and at some distance away. The third anchor at $30 \mathrm{~m}$ added a redundancy to the monitoring system and allowed for measurement of displacements over a greater distance away from the fissure. Horizontal measurements of ground displacement at previously identified earth fissure locations should be performed by measuring changes in rod position using a depth micrometer and the reference table measurement apparatus.

\subsection{InSAR}

The use of repeat-pass InSAR to characterize the distribution and rate of regional ground subsidence is of profound significance in monitoring and managing the risks associated with ground subsidence and earth fissuring. The principal of interferometry is described by Gabriel and Goldstein (1988) and there are numerous examples of applying the InSAR methodology to characterizing land subsidence where Hoffmann et al. (2001) and Panda et al. (2013) provide good examples. Interferometry has the ability to detect and quantify minute changes in the elevation of terrain by comparing phase variances of satellite-based, side-looking radar data between orbits of a similar trajectory. InSAR is used to detect the rate and distribution of subsidence occurring in an area over the time periods covered by InSAR imagery. Several InSAR-based methodologies exist and may be useful to a given site depending on site conditions and available data. These methodologies include traditional 2-pass InSAR, stacked 2-pass InSAR interpretations, and various persistent scatter (PS) InSAR methods and algorithms. In the arid western regions of the USA, traditional 2-pass InSAR is often the most effective method.

InSAR data can be analysed by direct observation of interferograms, cross-sectional presentation of vertical change, and interactive three-dimensional presentation with contouring. These analyses can be used in a variety of ways, such as to support lineament analysis and reconnaissance, to com- pare with survey data, and to be used as a calibration tool for subsidence modelling. InSAR data analysis is particularly useful for assessing changes in the location or rate of regional ground deformation and to help refine characterization of bedrock/alluvial interfaces and general lithologic variations in the deep alluvium (Rucker et al., 2008; Weeks and Panda, 2004). Results from InSAR will depend on the site's terrain, ground and vegetation conditions, and sources of potential ground disturbance due to cultural interference such as agriculture or construction site grading.

\subsection{Borehole tiltmeters}

Borehole tiltmeters (BTMs) can be utilized to monitor ground deformation, particular when large infrastructure is involved and when large-scale failure is a concern. The authors are involved in a project that utilizes borehole tiltmeters as a major monitoring component at the location of a brine cavern with a potential to catastrophically fail and form a large sinkhole (AMEC, 2014). BTMs measure the angle of movement from the horizontal position in microradians $(\mu \mathrm{rad})$ and deliver the data collected to the onsite monitoring computer that is part of integrated early warning system.

\subsection{Microseismic array}

The deployment of a microseismic array can be a useful monitoring tool in some subsiding environments. The authors involved in a project that utilizes a microseismic array as a monitoring component at the location of a brine cavern with the potential to catastrophically fail and form a large sinkhole (AMEC, 2014). The microseismic array consists of the deployment of highly sensitive geophones that collect the acoustical signals generated by microseismic activity, or ground vibration, in and around the brine cavern. Each borehole microseismic array consists of four geophones or sensors, including three uniaxial geophones and one triaxial geophone. The system is designed to monitor seismic activity and local fracturing of rockmass at the site and the system's data processing routines are fully automated. Microseismic detection is based on an array of geophones instrumented at key locations. $P$ waves and $s$ waves are processed, and the system can automatically alert when wave amplitudes exceed set thresholds. The system transmits information from MS event signals as a voltage to a seismic recorder, which synchronizes the data with a GPS component and converts the data to a seismic signal. Processing software assigns a location and magnitude to each locatable microseismic event.

\subsection{Monitoring trenches/platforms}

At locations where regular inspections occur to identify signs of potential earth fissure activity, specifically designed monitoring trenches or platforms can be designed to facilitate the observation process. The intent of such a system is to provide 
visible access to a surface where ground cracking associated with earth fissures would be more easily observable if it were to develop. This may be in the form of permanent trenches that are excavated to a more cemented soil horizon or in the form of a large cleared area of ground. The authors annually monitor a site that includes two large monitoring trenches for this purpose. Care needs to be taken in regards to drainage of the trenches, growth of vegetation and other disturbances.

\subsection{Time-domain reflectometry}

TDR utilizes uses a pulsed electromagnetic signal along a coupled coaxial cable to detect reflected changes resulting from deformation. The authors have deployed a TDR system at two sites with the goal of utilizing it as an earlywarning and monitoring tool for discrete ground deformation related to ground subsidence and earth fissuring (AMEC, 2006, 2010). Both travel time and signal strength are measured. Travel time is used to determine position, with signal strength being an indication of the severity of the deformation. Signal strength is an approximate measure of deformation, therefore the TDR instrumentation should be viewed as a means to detect but not fully quantify deformation. The TDR system was designed such that should sufficient ground deformation occur to create a crack in the cemented soils, that crack would transmit itself through the controlled lowstrength material (CLSM) that the cable is encased in and be detected by a signal sent through the TDR cable. While the TDR system has proven effective in detecting cracks that form in the CLSM backfill material, it has proven to be more sensitive than anticipated. Cracks detected have been the result of shrinkage cracking within the CLSM material and not the cemented soils. The system was abandoned after several years due to the sensitivity to shrinkage cracks within the backfill material.

\subsection{Other methods}

Other methods that are often utilized to monitor land subsidence include borehole extensometers and permanent GPS stations that are widely utilized by groups such as the United States Geological Survey (LSCE et al., 2014; Galloway et al., 1999; Poland and Lofgren, 1984). These methods often provide highly accurate point-source data, however the cost of systems is often prohibitive for most applications.

Monitoring for specific types of infrastructure can allow for other methodologies to be applied to land subsidence and earth fissuring monitoring. These could include techniques utilized to monitor pipelines, sonar-based methodologies, LiDAR, techniques such as on-train instrumentation for rail infrastructure, and others. Additionally, it anticipated that many monitoring methods will become drone-based as the drone technology continues to develop.

\section{Conclusions}

The authors have successfully designed and implemented monitoring systems capable of quantifying rates and distributions of ground subsidence and detection of ground rupture at multiple locations throughout the Western USA for several types of infrastructure including dams, levees, channels, basins, roadways, and mining facilities. Effective subsidence and earth fissure monitoring requires understanding and quantification of historic subsidence, estimation of potential future subsidence, delineation of the risk for earth fissures that could impact infrastructure, and motivation and resources to continue monitoring through time. A successful monitoring system provides the means to measure ground deformation, grade changes, displacement, and anticipate and assess the potential for earth fissuring. Employing multiple methods, a monitoring strategy utilizes an integrated approach, including both regional and local measurements.

Various methods implemented include conventional practices and proven, instrumented in-ground sensing systems. The conventional techniques include repeat optical levelling and GPS surveys, ground reconnaissance, photo-geological analysis, groundwater monitoring, and tape-extensometers. Advanced techniques include the processing and interpretation of differential interferograms of repeat-pass, InSAR, borehole tiltmeters, microseismic arrays, excavation of monitoring trenches, and TDR.

\section{References}

AMEC (AMEC Earth \& Environmental): TDR Trench Investigation and cable Installation Report, McMicken Dam Post Design Completion, Prepared for the Flood Control District of Maricopa County, Arizona, Contract FCD 2004C068, Work Assignment No. 1, 11 April 2006.

AMEC (AMEC Earth \& Environmental, Inc.): McMicken Dam Instrumentation \& Monitoring Plan (Revision 2), Prepared for the Flood Control District of Maricopa County, Arizona, Contract FCD 2008C016, Work Assignment No. 8. AMEC Job No. 09117-01038, 18 June 2010.

AMEC (AMEC Earth \& Environmental, Inc.): Subsidence and Earth Fissure Risk Zoning Report, Final Design Level Geohazard Investigation, McMicken Dam, Prepared for the Flood Control District of Maricopa County, Arizona, Contract FCD 2011C005, Work Assignment No. 4, 28 February 2013.

AMEC (AMEC Earth \& Environmental, Inc.): Final Feasibility Study, I\&W Brine Cavern, Carlsbad, New Mexico, Prepared for the Oil Conservation Division, New Mexico Energy, Minerals, and Natural Resources Department, available at: ftp://164. 64.106.6/Public/OCD/Documents/I\&WBrineCavernProject/ I\&WBrineCavernProject-FeasibilityStudyFinal/

I\&WFeasibilityStudy_Final_081114.pdf, August 2014.

Beckwith, G. H., Slemmons, D. B., and Weeks, R. E.: Use of LowSun Angle Photography for Identification of Subsidence Induced Earth Fissures in Land Subsidence, in: Land Subsidence, edited by: Johnson, A. I., Proceedings of the Fourth International Sym- 
posium on Land Subsidence, 12-17 May 1991, Arvada, CO, Oxfordshire, UK: International Association of Hydrological Sciences Press, IAHS Publication No. 200, 261-269, 1991.

Fergason, K. C., Rucker, M. L., and Greenslade, M. D.: Investigative Procedures for Assessing Earth Fissure Risk for Dams and Levees, United States Society on Dams, 33rd Annual Meeting and Conference, 11-15 February 2013, Phoenix, AZ, 2013.

Fergason, K. C., Rucker, M. L., Panda, B., and Greenslade, M.: Investigative Procedures for Assessing Subsidence and Earth Fissure Risk for Dams and Levees, in: Engineering Geology for Society and Territory, Vol. 6, edited by: Lollino, G., Giordan, D., Thuro, K. Carranza-Torres, C., Wu, F., Marinos, P., and Delgado, C., International Association for Engineering Geology and the Environment, 2014.

Gabriel, A. K. and Goldstein, R. M.: Crossed Orbit Interferometry: Theory and Experimental Results From SIRB, Int. J. Remote Sens., 9, 857-872, 1988.

Galloway, D. L. Jones, D. R., and Ingebritsen, S. E.: Land subsidence in the United States, U.S. Geological Survey Circular 1182, 177 pp., 1999.

Hoffmann, J., Galloway D. L, Zebker, H. A., and Amelug, F.: Seasonal subsidence and rebound in Las Vegas Valley, Nevada, observed by synthetic aperture radar interferometry, Water Resour. Res., 37, 1551-1566, 2001.

Keaton, J. R., Rucker, M. L., and Cheng, S. S.: Geomechanical Analysis of an Earth Fissure Induced by Ground-Water Withdrawal for Design of a Proposed Ash and Sludge Impoundment, Southeastern Arizona, in: Land Subsidence Case Studies and Current Research: Proceedings of the Dr. Joseph F. Poland Symposium on Land Subsidence, edited by: Borchers, J. W., Association of Engineering Geologists, Star Publishing Company, Belmont, California, Special Publication No. 8, 217-226, 1998.

LSCE (Luhdorff \& ScalManini Consulting Engineers), Borchers, J. W., and Carpenter, M.: Land Subsidence from Groundwater Use in California, Full Report of Findings, California Water Foundation, April 2014.

Panda, B. B., Rucker, M. L., and Fergason, K. C.: InSAR as a Subsidence Characterization Tool for Flood Control Dam Studies, United States Society on Dams, 33rd Annual Meeting and Conference, 11-15 February 2013, Phoenix, AZ, 2013.

Poland, J. F. and Lofgren, B. E.: Case History No. 9.13. San Joachin Valley, California, U.S.A., in Guidebook to studies of land subsidence due to ground-water withdrawal, available at: http://wwwrcamnl.wr.usgs.gov/rgws/Unesco/PDF-Chapters/ Chapter9-13.pdf, last access: 31 August 2012, 1984.
Rucker, M. L. and Fergason, K. C.: Role of Practical Geophysics to Investigate and Mitigate a Distressed Flood Control Dam, for Association of State Dam Safety Officials Annual Conference, 25-30 September 2004, Pointe South Mountain Resort, Phoenix, Arizona, 2004.

Rucker, M. L. and Holmquist, O. C.: Surface Seismic Methods for Locating and Tracing Earth Fissures and other Significant Discontinuities in Cemented Unsaturated Soils and Earthen Structures, 4th International Conference on Unsaturated Soils, 2-6 April 2006, Carefree, Arizona, 2006.

Rucker, M. L. and Keaton, J .R.: Three-Dimensional Characterization with Limited Data: An Example from Playa-Lake Basin, Southeast Arizona, in: Transportation Research Record No. 1526, Soils, Geology, and Foundations, Engineering Technologies in Geotechnical Engineering, Transportation Research Board, National Research Council, National Academy press, Washington, D.C., 1996.

Rucker, M. L. and Keaton, J .R.: Tracing an Earth Fissure Using Seismic-Refraction Methods with Physical Verification, in: Land Subsidence Case Studies and Current Research: Proceedings of the Dr. Joseph F. Poland Symposium on Land Subsidence, edited by: Borchers, J. W.,Association of Engineering Geologists, Star Publishing Company, Belmont, California, Special Publication No. 8, 207-216, 1998.

Rucker, M. L., Greenslade, M. D., Weeks, R. E., Fergason, K. C., and Panda, B. B.: Geophysical and Remote Sensing Characterization to Mitigate McMicken Dam, in: GeoCongress 2008: Geosustainability and Geohazard Mitigation (GSP 178), edited by: Reddy, K. R., Khire, M. V., and Alshawabkeh, A. N., American Society of Civil Engineers, 207-214, 2008.

Rucker, M. L., Fergason, K. C., Greenslade, M. D., and Hansen, L. A.: Characterization of Subsidence Impacting flood Control Dams and Levees, United States Society on Dams, 33rd Annual Meeting and Conference, 11-15 February 2013, Phoenix, AZ, 2013.

Weeks, R. E. and Panda, B.: Defining Subsidence-Induced Earth Fissure Risk at McMicken Dam, for Association of State Dam Safety Officials Annual Conference, 25-30 September 2004, Pointe South Mountain Resort, Phoenix, Arizona, 2004.

Weeks, R. E., Panda, B., and Fergason, K. C.: Application of Synthetic Aperture Radar Interferometry (InSAR) in Defining Mine-Related Ground Deformation and Subsidence Hazards, for 5th Biennial Workshop Mines - Interstate Technical Group on Abandoned Underground Mines (ITGAUM) - Abandoned Underground Mine Workshop, 21-23 April 2004, Tucson, Arizona, U.S. Department of Transportation, Federal Highway Administration and Arizona Department of Transportation, 2004. 